\title{
Public Inflation Aversion and the Political Economy of Macroeconomic Policymaking
}

\author{
Kenneth Scheve
}

\begin{abstract}
Do the macroeconomic priorities of citizens differ across countries? If so, what accounts for this variation and what are its consequences for explanations of the choice of monetary institutions, macroeconomic policy, and international monetary cooperation? This article uses survey data from twenty advanced economies to examine individual preferences about macroeconomic priorities. The analysis establishes three key findings. First, the results suggest that economic context, defined by inflation and unemployment performance, has a substantial impact on the public's economic objectives in a way that is broadly consistent with the specification of utility/ loss functions in the theoretical political economy literature. Second, the results suggest that there is significant cross-country variation in inflation aversion, controlling for economic context. Third, some of this variation is accounted for by nationallevel factors affecting the aggregate costs of inflation and unemployment. These results have significant implications for optimal monetary policymaking, the explanation of variation in economic outcomes, and for accounts of the choice of institutional frameworks for policymaking.
\end{abstract}

Public preferences about macroeconomic priorities are an essential input for democracies into any explanation of the choice of monetary institutions, the extent of international monetary cooperation, the adoption of macroeconomic policies, and the robustness of economic performance. Whether the objective is explaining institutional choice, international coordination, policy choice, outcomes, or the associated political conflict over these decisions, political economy models must specify the preferences of all the relevant actors. Although the preferences of politicians, central bankers, and even interest groups are often discussed in these models, the investigation of these research questions has largely taken place with-

I thank the Bank of England, the Center for Basic Research in the Social Sciences, and the Institution for Social and Policy Studies for research support, and Jim Alt, Andrew Bailey, Bill Bernhard, Lawrence Broz, John Freeman, Jeff Frieden, Jim Granato, Shigeo Hirano, David Lake, Jeff Lax, Simon Price, Rose Razaghian, Ron Rogowski, David Stasavage, Gabriel Sterne, Mike Tomz, Jim Vreeland, the editor, and two anonymous reviewers for helpful comments. All views expressed are those of the author and do not represent those of the Bank of England.

International Organization 58, Winter 2004, pp. 1-34

(C) 2004 by The IO Foundation.

DOI: $10.1017 / \mathrm{S} 0020818304581018$ 
out reference to what the public thinks about economic policy objectives. When the preferences of citizens have been included in this research, those preferences are usually assumed rather than grounded in empirical evidence. What are the macroeconomic priorities of individual citizens? Are views about macroeconomic priorities similar across different individuals, or are there important divisions? Do preferences vary across countries, and, if so, what accounts for this variation?

This article uses individual-level survey data from twenty advanced economies to address these questions. There are three main empirical results. First, the findings suggest that economic context, defined by inflation and unemployment performance, has a substantial impact on the public's economic objectives in a way broadly consistent with the specification of utility/loss functions in the theoretical political economy literature. Rising and more volatile inflation is more costly, and the public places greater emphasis on low inflation as prices increase more rapidly. Similarly, as unemployment rises, reducing unemployment becomes a greater priority. These results are generally consistent with a very large public opinion literature, though this study extends those results by relying on comparable data from twenty advanced economies.

Second, the findings in this article suggest that there is significant cross-country variation in inflation aversion, controlling for economic context. The mass public's assessment of the relative costs of inflation and unemployment varies substantially across countries. The third empirical result is that some of this cross-national variation is accounted for by national-level factors affecting the aggregate costs of inflation and unemployment. The empirical estimates in this article suggest that the demand for government revenue and the size and structure of the financial sector partially explain cross-country variation in inflation aversion, controlling for economic context.

Cross-country variation in inflation aversion while controlling for economic context has significant implications for optimal monetary policymaking, for explanations of variation in economic outcomes, and for theoretical political economy models of alternative institutional frameworks for policymaking. In standard macroeconomic models based on rational expectations, optimal policy-whether chosen period by period or by precommitment to an optimal rule-depends on levels of inflation aversion in society. In particular, the optimal policy will stabilize output in response to shocks more aggressively the lower inflation aversion is in society. The cross-country variation in inflation aversion documented in this article suggests that optimal policy responses will differ across countries simply as a function of preferences. This finding implies that both prescriptions for policy and explanatory models of variation in macroeconomic outcomes should take into account country differences in inflation aversion. The implications for the adoption of alternative institutions for monetary policymaking are also straightforward. For example, economic arguments about joining monetary unions are often organized around determining if the countries in question constitute an optimal currency area. This evaluation has focused a great deal of attention on the degree to which economic activity in the parts of the union is correlated, because one of the major 
costs to currency unions is giving up the ability to use the exchange rate and monetary policy to stabilize output and employment. The empirical results in this article suggest that assessments of the costs and benefits of currency unions must also take into account variation in inflation aversion, as these differences affect the costs and benefits to all members adopting a single policy. Moreover, crosscountry differences in inflation aversion will generate conflict when the members of currency unions select the policymaker(s) for the union. How conservative the optimal central banker is depends on the levels of inflation aversion in society. Variation in those preferences across the members of the currency union will generate ongoing conflict about who best fills the role of the central banker.

The remainder of the article is organized into six sections. The next section defines inflation aversion and the following section provides a theoretical framework for explaining its variation across individuals and countries. The next two sections discuss the data and model specifications and present the empirical results. The penultimate section discusses some of the theoretical and methodological implications of the findings, and the final section concludes.

\section{Defining Inflation Aversion}

The substantial literature on the political economy of macroeconomic policymaking provides a theoretical structure for the analysis of variation in macroeconomic priorities. ${ }^{1}$ In these models, voters and policymakers are assumed to have utility or loss functions that depend on inflation and output or unemployment. The exact functional form of the utility or loss functions varies across different contributions to the literature, but the main intuition is that utility decreases in the inflation rate and the unemployment rate and increases in the level of output. Typically, only a single indicator of real economic performance-unemployment or output growth-is included in any particular specification of the utility or loss functions. ${ }^{2}$ A common specification, the Barro-Gordon loss function, is the following equation: ${ }^{3}$

$$
L=a\left(U_{t}-k U_{t}^{n}\right)^{2}+b\left(\pi_{t}\right)^{2}
$$

1. Among the many important theoretical contributions to this literature, see Alesina 1987; Barro and Gordon 1983a and 1983b; Hibbs 1987a and 1987b; Kydland and Prescott 1977; Lohmann 1992; Rogoff 1985; and Walsh 1995.

2. Given the macroeconomic models employed in the literature, the choice of indicators of real economic activity does not matter for key theoretical results, although in richer models of the economy it could, of course, make a difference. This article follows much of the literature by focusing attention on unemployment as the relevant indicator of real economic activity, in part because it is the most salient measure in public discussions of the economy.

3. Barro and Gordon 1983b. 
where $U_{t}$ is the employment rate; $U_{t}^{n}$ is the natural rate of unemployment; $\pi_{t}$ is the inflation rate; $a$ and $b$ indicate the relative weight of the first and second terms in the loss function and are assumed to be strictly greater than 0 ; and $k$ indicates the extent of distortions, such as unemployment compensation and income taxation, that make the natural rate exceed the efficient or socially optimal rate and is generally assumed to be less than 1 but greater than or equal to 0 . This loss function values price stability and full employment, and the ratio of the parameters $a$ and $b$ captures the benefit of employment relative to the cost of higher inflation. These parameters therefore indicate the voter's or policymaker's inflation aversionthat is, how the individual assesses the relative costs and benefits of inflation and unemployment. The subject of this article is an empirical investigation into whether inflation aversion varies across countries, and if so, what accounts for that variation. ${ }^{4}$

\section{What Accounts for Cross-Country Variation in Inflation Aversion?}

This section discusses the theoretical determinants of inflation aversion. If there is cross-country variation in the public's macroeconomic priorities, what are its determinants? The explanatory framework focuses on those factors that affect perceived costs of inflation and unemployment at both the individual and national level.

How individuals assess the importance of alternative macroeconomic policy objectives should obviously depend on current economic performance. Because the costs of inflation increase in the inflation rate and the costs of unemployment increase in the unemployment rate, public concern about these economic outcomes will vary accordingly. Consistent with these observations, a large body of public opinion research has shown that individuals dislike unemployment, low growth, and inflation. ${ }^{5}$ Note, however, that the responsiveness of public concern about inflation and unemployment to current performance does not reflect variation in inflation aversion as defined in the previous section. The Barro-Gordon loss function in equation (1) and similar utility/loss functions in the literature include unemployment and inflation as arguments in the function. Inflation aversion itselfassessments of the relative costs and benefits of inflation and unemployment-

4. The loss function in equation (1) is actually symmetric for unemployment, with departures from the natural rate in either direction generating losses. Differences in both directions are weighed equally for the special case in which $k=1$. Consequently, to say voters like full employment means they like unemployment equal to the natural rate. In most of the theoretical political economy literature, $k$ is assumed to be less than one (for example, the existence of a time consistency problem in monetary policymaking depends on $k$ being less than one), and it is accurate to say voters especially dislike outcomes in which unemployment is high.

5. See, for example, Alt 1979; Anderson 1995; Di Tella, MacCulloch, and Oswald 2001; Hibbs 1987a and 1987b; Kramer 1971; Lewis-Beck 1988; Powell and Whitten 1993; Sekhon 1999; and Shiller 1997. 
measures how a given level of current unemployment and inflation affects individual utility. In discussing the determinants of variation in inflation aversion across individuals and countries, one needs to know why, for a given level of inflation and unemployment, some individuals and countries seem to have different levels of concern about these economic objectives. ${ }^{6}$

\section{Individual-Level Determinants}

One possible explanation for cross-national variation in inflation aversion is differences in the composition of individuals within a country. Previous research has found that the distributional consequences of inflation and unemployment affect individual macroeconomic priorities. ${ }^{7}$ If the proportion of individuals relatively more exposed to the costs of inflation (unemployment) is greater in one country than another, then average inflation aversion in that country can be expected to be higher (lower).

Previous research suggests that individuals differ in their exposure to the distributional consequences of inflation and unemployment through both their position in the labor market and their ownership of nominal assets and liabilities. The effect of labor market position is straightforward-individuals vary in their risk of unemployment. Higher national unemployment typically is not distributed equally across labor market participants. For example, all else being equal, low-income individuals have a higher probability of unemployment. Moreover, differences by income group in concern about unemployment and inflation may also be because of wage effects. In some countries, periods of high unemployment have been associated with increasing wage and income inequality. ${ }^{8}$ Consequently, lower-income groups may be relatively more concerned about unemployment, generating a positive relationship between income and inflation aversion. ${ }^{9}$ The more general point

6. The Barro-Gordon loss function in equation (1) suggests that economic context may not be a simple function of current inflation and unemployment. It is possible that it is only departures of unemployment from the natural rate that are perceived to be losses (this would be true if the parameter $k=1$ ). This would require individuals to be fairly sophisticated, in that their preference for employment, and growth is only for those levels consistent with stable prices. Moreover, Barro and Gordon $1983 \mathrm{~b}$ and others have typically assumed that because of existing labor market distortions, the natural rate is above its efficient or socially optimal level. Consequently, when the natural rate is higher, the costs of unemployment are higher, and so this may be a relevant consideration as individuals set their macroeconomic objectives. These considerations suggest that the natural rate of unemployment may be a determinant of the economic context that affects individuals' concerns about inflation and unemployment. This possibility is addressed in some of the empirical work described below.

7. See Hibbs 1987a and 1987b; Hibbs, Rivers, and Vasilatos 1982; and van Lelyveld 1999.

8. See Blinder and Esaki 1978; Hibbs 1987b; and Hibbs and Dennis 1988.

9. Alternative hypotheses about the relationship between income and inflation aversion are prevalent. It may be the case that inflation is correlated with rising/high income inequality as the rich find it easier than the poor to protect themselves against real income declines from inflation. This argument suggests a possible negative relationship between income and the demand for low inflation. Alternatively, the relationship may be nonlinear, with low- and high-income individuals being most concerned about inflation and middle-income citizens being most concerned about unemployment. See Alt 1979. 
is this: how national unemployment levels are likely to affect individuals' labor market outcomes will differ across individuals, and these differences will affect individual macroeconomic priorities. ${ }^{10}$

Besides distributional consequences in the labor market, it has long been recognized theoretically that the relative concern of individuals about inflation and unemployment may depend on the ownership of nominal assets and liabilities. Unexpected inflation redistributes wealth and income through all nominal assets and liabilities when contracts are less than fully indexed. Debtors and those who pay fixed nominal incomes gain at the expense of creditors and those who receive fixed incomes. These redistributional effects of inflation are likely to affect the macroeconomic priorities of individuals. Specifically, those individuals who own nominal assets and receive fixed incomes are likely to be more inflation-averse, while those who are debtors and pay fixed incomes are likely to be less so. ${ }^{11}$

In addition to, or perhaps as part of, the distributional explanations for variation in individual inflation aversion, the macroeconomic priorities of individuals are often thought to reflect the political coalitions with which they identify. There is substantial evidence that parties of the left and right have systematically different preferences about macroeconomic objectives, with parties of the right being more inflation-averse than parties of the left. ${ }^{12}$ Consistent with this literature, those individuals who identify themselves as ideological conservatives or as members of right parties may be relatively more inflation-averse. The hypothesized relationship must, however, be interpreted with some care. It is unclear to what extent political ideology explains macroeconomic preferences. Ideology and partisanship are sometimes thought to be the result of early socialization (particularly the influence of parent ideology on children), and thus it would be accurate to say ideology and partisanship explain preferences. Other accounts see these variables as summary statistics for policy preferences or running tallies of political preferences that are constantly updated. From this perspective, it is not clear that any correlation between political ideology and measures of inflation aversion indicates evidence of an explanation of individual macroeconomic priorities.

The key question asked in this article about individual differences in inflation aversion is whether the characteristics that account for these differences also explain variation across countries. This is, of course, only possible if there is substantial variation across countries in the composition of citizens with the relevant characteristics.

10. Given that risks of unemployment may vary across individuals according to other demographic characteristics besides income, such as education and gender, the empirical analysis will investigate individual variation in inflation aversion with respect to these characteristics in addition to income and, of course, current employment status.

11. Scheve 2003 shows strong evidence that nominal asset owners are relatively more inflationaverse in the United Kingdom, but finds no evidence that those with nominal liabilities are less so.

12. See Alesina, Roubini, and Cohen 1997; Alt 1979; and Hibbs 1987a and 1987b. 


\section{National-Level Determinants}

Another possible explanation of cross-national differences in inflation aversion concerns characteristics of the national economic and political environment that affect the actual costs of inflation and unemployment. If inflation (unemployment) is simply more costly to all individuals in a particular country, then average inflation aversion can be expected to be higher (lower).

One such country-level characteristic is based on variation in the demand for government revenue. Current research on the costs of inflation focuses attention on the effects of the interaction between inflation and the tax system on welfare. This literature shows that this interaction can have substantial negative effects. ${ }^{13}$ These negative effects are balanced against the recognition that inflationary finance of government expenditures can have some benefits. If nondistortionary lump sum taxes are not available, then raising revenue through the inflation tax may be better than other forms of taxation that distort economic behavior. In this scenario, inflation is still costly, and these costs will limit the extent to which it should be used as a source of revenue. Nonetheless, there are potential benefits to inflation given that existing tax structures are distortionary. How significant this consideration is in evaluating the relative costs of inflation and unemployment is likely to depend on the demand for government revenue. Suppose this demand is assumed to be exogenous, depending on tastes for public services and current or past military needs. Two reasonable indicators of this demand are total government expenditures and total government debt. This suggests that individuals in countries with higher government expenditures and debt are likely to be, all else being equal, less inflation-averse.

Public assessments of the relative costs of inflation and unemployment may also depend on how open the national economy is to international trade. The general intuition in the literature is that inflation is more costly in more open economies. ${ }^{14}$ The reasoning behind this hypothesis differs across contributions to this literature. However, the intuition that higher inflation is correlated with greater uncertainty about future inflation and greater real exchange-rate volatility, which is more costly in more open economies, is sufficient for this analysis. If so, individuals in more open economies may be more inflation-averse.

Another salient argument in the literature on the determinants of inflation outcomes is that the size and structure of the financial sector is an important factor affecting the choice of monetary institutions, policy, and ultimately economic outcomes. ${ }^{15}$ The claim is that the financial sector, particularly firms engaged in traditional commercial lending with typically long-term assets and short-term liabilities,

13. See Feldstein 1997; and Bakhshi, Haldane, and Hatch 1997.

14. See Frieden 1991 and 2002; Lane 1997; and Romer 1993.

15. Posen 1995. 
has a strong preference for price stability. ${ }^{16}$ Strictly interpreted, this argument might apply only to the distribution of preferences about macroeconomic prioritiesthat is, it implies that the financial sector is more inflation-averse than the rest of society. However, a large financial sector might affect average levels of inflation aversion at the margin, both directly through individuals employed in the sector and indirectly through the sector's influence on the media.

Finally, cross-national variation in inflation aversion may be a function of differences in historical economic performance. Two contradictory arguments are made with respect to the impact of national historical economic performance on mass attitudes about inflation. The most common argument is that in those countries that have experienced significant inflationary periods, individuals are more concerned about the potential of rising prices to foster economic and political instability. In such countries, there is expected to be generally greater demand for low inflation. One reason for this effect may simply be pure learning on the part of the public and policymakers. Alternatively, this effect may be due at least partly to constructed and politically contested interpretations in which influential ideas help shape the public's view of historical economic performance and thus how that experience informs assessments about the relative costs and benefits of inflation and unemployment. ${ }^{17}$ The alternative argument is that in countries that have had substantial inflation in the past, ways of reducing the costs associated with rising prices have been developed, and thus individuals in those countries are generally less concerned about it. Given these two sets of considerations, the net effect of historical economic performance is likely to differ across cases as the relative magnitude of the two contradictory effects of experience with inflation is not clear and may vary across time and countries. ${ }^{18}$

In summary, the observation that citizens generally dislike inflation and unemployment does not imply that their assessments of the relative importance of these objectives do not vary in important ways. There are substantial theoretical reasons to think that the costs of inflation and unemployment differ across coun-

16. Some financial sector business activities, such as foreign exchange trading, may benefit from higher and more volatile inflation, so the emphasis here is on traditional commercial banking businesses.

17. See Hall 1993; Hayo 1998; and McNamara 1999. More generally, differences in public information sets in particular countries may lead individuals to have different priorities. Historical economic performance is just one possible source of variation in public information. The media, professional economists, and political elites may also have an effect. See Shiller 1997.

18. The discussion in this section has not exhausted the national-level factors that may affect inflation aversion. One interesting extension that is left for future research is how particular combinations of wage-bargaining institutions and monetary policy institutions may condition opinion formation about macroeconomic priorities. See, for example, Garrett and Way 1999; Iversen 1999; and Franzese 2002. The results reported in this article are robust to including these variables, but these unreported regression specifications must be viewed with some skepticism. As argued in the penultimate section of this article, monetary frameworks should be viewed as consequences of, among other things, national levels of inflation aversion. This does not mean that there cannot be feedback effects from institutions to public levels of inflation aversion, but it does mean that to estimate such an effect requires valid instrumental variables and/or perhaps more data over time than was available in this study. 
tries and individuals and thus systematically affect the public's macroeconomic priorities.

\section{Data and Econometric Model}

To provide evidence of cross-country variation in public inflation aversion and to evaluate individual and national-level determinants of this variation, I examine survey-based measures of inflation aversion in twenty advanced economies in selected years between 1976 and 1997. The data for this analysis are from five crossnational surveys that included respondents in Australia, Austria, Belgium, Canada, Denmark, Finland, France, Germany, Greece, Ireland, Italy, Japan, the Netherlands, New Zealand, Norway, Portugal, Spain, Sweden, the United Kingdom (UK), and the United States. The surveys are Eurobarometers (EB) 5.0 (1976) and 48.0 (1997) and the 1985, 1990, and 1996 waves of the International Social Survey Program (ISSP). ${ }^{19}$ Each country is represented in at least one of the five surveys, and one country, Germany, is included in all five. In total, the data set comprises forty-four surveys in the twenty countries. The EB and ISSP are cross-country surveys that collect information on the current economic and political opinions of representative samples of individuals in each country. ${ }^{20}$

The theoretical dependent variable for the study is inflation aversion. To measure this variable, I use responses to survey questions about macroeconomic priorities that are generally in the form of the following item:

What do you think the (NATIONAL) government should give greater priority to, curbing inflation or reducing unemployment $?^{21}$

I constructed the variable INFLATION PRIORITY equal to 1 if the respondent gave the "inflation" response and 0 if he or she gave the "unemployment" response. This question requires respondents to reveal explicitly how important they think low inflation is relative to the problem of unemployment. In this sense, the measure is consistent with the inflation aversion parameters $a$ and $b$ specified in equation (1) above. Inflation aversion is increasing in the INFLATION PRIORITY variable.

The key criterion in assessing whether this is a good measure of inflation aversion, as defined above, is if responses to the question will be sensitive to indi-

19. See Rabier and Inglehart 1976; Melich 1997; and ISSP 1985, 1990, and 1996.

20. Note that this article limits its analysis to large advanced industrial democracies. Consequently, some available data from the EB and ISSP surveys is excluded. Specifically, EB data from Luxemburg and ISSP data from several transition and lesser-developed economies is not used in the analysis. See the Appendix for further details about the construction of the data set.

21. This is the exact question wording from the Eurobarometer 5.0. Each of the surveys asks respondents an equivalent question. The exact question wording for each of the five surveys is reported in the Appendix. The Appendix reports how the slight variations in the wording of each of the questions across the five surveys was dealt with, and how the statistical analyses take into account additional uncertainty generated by these differences. 
viduals' assessments of the relative costs and benefits of inflation and unemployment. This expectation seems at least ex ante reasonable. ${ }^{22}$ Note that consistent with the literature, the objective is to measure preferences about inflation and unemployment. These preferences are of interest for, and in fact part of, the utility functions in standard economic models for which there is no long-run tradeoff between inflation and unemployment.

It must be recognized, however, that individual responses to this question depend on the economic context in which the question is asked. Consequently, answers to this question, taken in isolation, can be thought of as eliciting the individual's context-specific inflation aversion. Just as utility in the theoretical literature depends on current inflation and unemployment rates, answers to this question will depend on the same factors. Inflation aversion itself-assessments of the relative costs and benefits of inflation and unemployment - is therefore measured by responses to the question controlling for the current economic context, as will be done in the analysis below. ${ }^{23}$

The analysis investigates the individual- and national-level determinants of individual macroeconomic priorities, as measured by the INFLATION PRIORITY variable, across the twenty advanced economies included in the data set. The theoretical discussion emphasizes that how important individuals think low inflation is should vary with current economic performance, defined by inflation and unemployment. The INFLATION variable is the annual percentage change in the consumer price index as published in the World Bank's World Development Indicators. ${ }^{24}$ The UNEMPLOYMENT variable is equal to the current unemployment rate as reported in

22. See Hibbs 1979 and van Lelyveld 1999 for use of similar measures.

23. There are at least three alternative strategies for measuring inflation aversion. The first is to ask individuals survey questions specifically about inflation without reference to other macroeconomic policy objectives. The major disadvantage of this approach is that there is no budget constraint or price explicit in the question. These sorts of questions often fail to reveal much information, as variation in responses is low. The survey evidence suggests that most people can be expected to think prices should be kept under control, even if they disagree strongly about the relative importance of various economic policy objectives. A variant of this approach uses survey questions about the importance of inflation relative to noneconomic values. See, for example, Hayo 1998. This type of question has a price, but not one that maps to the definition of inflation aversion described above. The second approach is to measure the sensitivity of government popularity to inflation performance. See, for example, Hibbs, Rivers, and Vasilatos 1982. While this method avoids problems with the wording in survey questions, the relationship between government popularity and inflation depends on each country's political and economic institutions, and this variation makes it extremely difficult to construct comparable measures across countries. The third alternative, implemented by Di Tella, MacCulloch, and Oswald 2001, is to estimate the sensitivity of individuals' reported "happiness" or "life satisfaction" to inflation and unemployment. This approach also avoids some problems with the wording in survey questions (but see King, Murray, Salomon, and Tandon forthcoming) and is well suited to producing a single estimate of how inflation and unemployment affect welfare. However, this approach does not allow analysis of variation in macroeconomic priorities across individuals, which is central to this article. Nonetheless, as Di Tella, MacCulloch, and Oswald 2001 indicate, the approaches are complementary.

24. World Bank 2001. 
the OECD Statistical Compendium. ${ }^{25}$ The expectation is that the INFLATION variable will, all else being equal, be positively correlated with the dependent variable INFLATION PRIORITY, while UNEMPLOYMENT will be negatively correlated with INFLATION PRIORITY.

The theoretical discussion also noted that individuals are expected to vary in inflation aversion as a consequence of characteristics that affect the perceived costs of inflation and unemployment at the individual level. Most importantly, variation among individuals is expected to be a function of the distributive effects of inflation and unemployment. Individual variation may, if the distribution of the relevant individual characteristics varies enough across countries, account for crossnational differences in inflation aversion.

To test these hypotheses about the role of individual characteristics, I constructed measures of income, labor force status, age, sex, education, and political ideology. The variable INCOME QUARTILE ranges from 1 to 4 and indicates whether the respondent's income is in the first, second, third, or fourth quartile of the income distribution for the respondent's country. Because low-income individuals are generally thought to have a higher probability of unemployment, and because high unemployment has been associated with increasing wage inequality in some countries, I hypothesize that INCOME QUARTILE will be positively correlated with inflation aversion. UNEMPLOYED is a dichotomous variable equal to 1 if the respondent is currently unemployed and equal to 0 if otherwise. This variable measures the individual's exposure to unemployment based on his or her current labor force status. Consequently, I expect UNEMPLOYED to be, controlling for other factors, negatively associated with the dependent variable INFLATION PRIORITY.

The variable AGE equals the respondent's age in years, and GENDER is a dichotomous variable equal to 1 for females and 0 for males. EDUCATION YEARS is an ordered categorical variable with nine categories corresponding to increasing years of formal education. Differences in inflation aversion according to these demographic characteristics are likely a function of distributive effects not captured by the measures of income and labor market position used in the analysis, and of systematic differences in how various types of individuals perceive the relative costs of inflation and unemployment. For example, older individuals are more likely to have significant nominal assets and/or to rely on fixed incomes. Moreover, individuals who have lived during periods of substantial, disruptive episodes of inflation are more likely to believe that low inflation is a critical policy objective than those who have not. Similarly, women have more volatile employment experiences than men, controlling for skill and experience, in many countries. These differences may lead to variation in preferences about macroeconomic priorities with women being less inflation-averse than men. Education is a common measure of both labor market skills and cognitive abilities. To the extent that it is a

25. Unless otherwise stated, the OECD Statistical Compendium 2001 is the source for all the aggregate economic measures described below. 
skill measure, education likely has effects on inflation aversion similar to those of income.

Finally, two measures were constructed to test the hypothesis that the political coalitions with which individuals identify may affect their macroeconomic priorities. POLITICAL IDEOLOGY is a 10 -point measure with 1 indicating that respondents placed themselves at the far left of the left/right scale and 10 corresponding to the far right. PARTY is a 5-point scale constructed by first determining what political party the respondent identified with and then placing the party on a 5-point left/right scale. These variables are hypothesized to be positively correlated with the dependent variable INFLATION PRIORITY, consistent with the literature on partisan patterns of economic policymaking. ${ }^{26}$

The theoretical discussion also suggests that the costs and benefits of inflation may vary across countries according to national-level political and economic characteristics. One such characteristic may be the demand for government revenue. I constructed two indicators of this demand. GOVERNMENT SPENDING is equal to total government expenditures as a percentage of gross domestic product, and DEBT is equal to total government debt, also as a percentage of gross domestic product. Because one of the hypotheses of this article is that increasing demand for government revenues increases the incentives for inflationary finance as an alternative to distortionary taxes, I expect that both these measures will be negatively associated with the INFLATION PRIORITY variable.

To evaluate the hypothesis that inflation may be more costly in more open economies and thus may lead the public to be more inflation-averse in countries more exposed to trade, I constructed the variable TRADE OPENNESS, equal to imports plus exports as a percentage of gross domestic product. This variable is hypothesized to be positively correlated with INFLATION PRIORITY. The theoretical discussion also considered the possibility that the size and structure of the financial sector may influence the public's perceptions of the relative costs of inflation and unemployment. The variable FINANCIAL EMPLOYMENT is equal to total employment in the financial sector as a percentage of total civilian employment, and broadly measures the size of this sector. I expect that this variable will be positively associated with the measure of inflation aversion, INFLATION PRIORITY.

Table 1 reports the summary statistics of the inflation aversion measure and the explanatory variables. The empirical work aims to see how different factors affect perceptions of the costs and benefits of inflation and unemployment, and thus the probability that an individual places priority on price stability. The dependent variable INFLATION PRIORITY equals 1 when a respondent gives the "inflation" response and 0 for the "unemployment" response. Then $E\left(\right.$ INFLATION PRIORITY $\left._{i}\right)=$

26. See Alesina 1987; Alesina, Roubini, and Cohen 1997; and Hibbs 1987a and 1987b. One set of hypotheses about individual variation in inflation aversion that cannot be tested in these data is the impact of ownership of nominal assets and liabilities. Scheve 2003 demonstrates a strong correlation between nominal asset ownership and inflation aversion. None of the survey data in this article report detailed information on respondents' nominal assets and liabilities. 
TABLE 1. Summary statistics

\begin{tabular}{lrc}
\hline Variable & Mean & $\begin{array}{c}\text { Standard error } \\
\text { of mean }\end{array}$ \\
\hline INFLATION PRIORITY & 0.387 & 0.002 \\
INCOME QUARTILE & 2.453 & 0.005 \\
UNEMPLOYED & 0.047 & 0.001 \\
AGE & 44.620 & 0.075 \\
GENDER & 0.512 & 0.002 \\
EDUCATION YEARS & 4.393 & 0.013 \\
POLITICAL IDEOLOGY & 5.409 & 0.010 \\
PARTY & 2.906 & 0.005 \\
ObSerVations & 55,194 & \\
& 4.425 & 0.606 \\
INFLATION & 8.785 & 0.618 \\
UNEMPLOYMENT & 38.017 & 1.160 \\
GOVERNMENT SPENDING & 65.306 & 3.751 \\
DEBT & 63.370 & 4.645 \\
TRADE OPENNESS & 8.338 & 0.397 \\
FINANCIAL EMPLOYMENT & 44 & \\
ObSERVATIONS & & \\
\hline
\end{tabular}

Note: These summary statistics are multiple-imputation estimates based on five imputed data sets.

$\operatorname{Pr}\left(\right.$ INFLATION PRIORITY $\left.=1 \mid \psi_{i}\right)=\psi_{i}$, where $i$ indexes each individual observation and $\psi_{i}$ equals the probability that an individual gives the "inflation" response. I model the variation in $\psi_{i}$ according to the logistic form with $\psi_{i}=1 /[1+$ $\left.\exp \left(-x_{i} \beta\right)\right]$. In this expression, $x_{i}$ is a vector of explanatory variables hypothesized to effect the probability of placing priority on inflation, and $\beta$ is a vector of effect parameters. I estimate these effect parameters using logit regressions. Further, because some of the key independent variables are country-level aggregate measures, it is important to consider the possibility that disturbances will be correlated within countries. If the disturbances are correlated within groupings that are used to merge aggregate data with individual-level data, then standard errors from the usual maximum likelihood estimation of the logit model can be seriously biased downwards. ${ }^{27}$ The standard errors reported in this analysis adjust for clustering by country and require the much weaker assumption that errors are independent across countries but not necessarily across every survey respondent within a country.

The analysis is based on five models (Models 1 through 5) defined by five alternative sets of explanatory variables. Model 1 includes the measures of economic context, INFLATION, and UNEMPLOYMENT, as well as a dichotomous variable indicating whether the respondent was queried in the 1980s, a similar indicator

27. See Moulton 1990 for a discussion of this effect for ordinary least squares regression. 
for the 1990s, and a series of dichotomous variables for each country in the analysis except the UK. Model 2 adds to this initial specification individual variables measuring labor market exposure and demographic characteristics. Models 3 and 4 add to this specification the two different measures of the respondent's political conservatism, POLITICAL IDEOLOGY and PARTY, respectively. Model 5 adds to Model 2 the variables DEBT, GOVERNMENT SPENDING, TRADE OPENNESS, and FINAnCial Employment. Table 2 shows the hypothesized sign for each of the regressors.

\section{Empirical Results}

The logit regression coefficient estimates for Models 1 through 5 are reported in Tables 3, 4, and 5. The results suggest that economic context has a substantial impact on the public's macroeconomic priorities in a way broadly consistent with the specification of utility/loss functions in the theoretical political economy literature. Rising and more volatile inflation is more costly, and the public places greater emphasis on low inflation as prices increase more rapidly. Similarly, as unemployment rises, reducing unemployment becomes a greater priority. The analysis also reveals that there is substantial cross-country variation in macroeconomic priorities, controlling for economic context. The findings indicate that nationallevel factors that likely affect the relative costs of inflation and unemployment on national economic welfare account for some of this variation. Further, variation in individual characteristics that affect the distributive consequences of inflation and unemployment and thus shape how individuals weigh different economic objectives helps explain individual-level variation in macroeconomic priorities but does not account for much of the cross-country variation.

TABLE 2. Hypothesized sign of independent variables

\begin{tabular}{ll}
\hline Independent variable & Hypothesized sign \\
\hline & \\
INFLATION & Positive \\
UNEMPLOYMENT & Negative \\
DEBT & Negative \\
GOVERNMENT SPENDING & Negative \\
TRADE OPENNESS & Positive \\
FINANCIAL EMPLOYMENT & Positive \\
INCOME QUARTILE & Positive \\
UNEMPLOYED & Negative \\
AGE & Positive \\
GENDER & Negative \\
EDUCATION YEARS & Positive \\
\end{tabular}


TABLE 3. Determinants of inflation aversion: Model 1

\begin{tabular}{|c|c|c|c|}
\hline \multirow[b]{2}{*}{ Regressor } & \multicolumn{3}{|c|}{ Model 1} \\
\hline & Coefficient & S.E. & $p$-value \\
\hline Inflation & 0.064 & 0.022 & 0.003 \\
\hline Unemployment & -0.059 & 0.026 & 0.024 \\
\hline $1980 \mathrm{~s}$ & 0.164 & 0.188 & 0.384 \\
\hline $1990 \mathrm{~s}$ & 0.371 & 0.169 & 0.028 \\
\hline Australia & 0.347 & 0.042 & 0.000 \\
\hline Austria & -0.318 & 0.172 & 0.065 \\
\hline Belgium & -0.291 & 0.117 & 0.013 \\
\hline Canada & 0.100 & 0.126 & 0.428 \\
\hline Denmark & -0.132 & 0.114 & 0.251 \\
\hline Finland & -0.570 & 0.175 & 0.001 \\
\hline France & -0.424 & 0.120 & 0.000 \\
\hline Germany & 0.296 & 0.126 & 0.019 \\
\hline Greece & -0.252 & 0.194 & 0.194 \\
\hline Ireland & -0.126 & 0.136 & 0.355 \\
\hline Italy & -0.497 & 0.060 & 0.000 \\
\hline Japan & 0.267 & 0.212 & 0.208 \\
\hline Netherlands & -0.439 & 0.118 & 0.000 \\
\hline New Zealand & 0.275 & 0.142 & 0.052 \\
\hline Norway & -0.069 & 0.103 & 0.503 \\
\hline Portugal & -0.757 & 0.142 & 0.000 \\
\hline Spain & -0.185 & 0.370 & 0.616 \\
\hline Sweden & -0.776 & 0.170 & 0.000 \\
\hline USA & 0.179 & 0.101 & 0.075 \\
\hline Constant & -0.469 & 0.341 & 0.169 \\
\hline Observations & 55,194 & & \\
\hline
\end{tabular}

Note: These results are multiple-imputation estimates of logit regression coefficients based on five imputed data sets. S.E. = standard error. The standard errors are country-clustered robust standard errors. The dependent variable is INFLATION PRIORITY.

For the Model 1 results reported in Table 3, the estimated coefficient for the variable INFLATION is 0.064 with a standard error of 0.022 . This indicates that increases in inflation are positively correlated with the probability that a respondent places priority on curbing inflation. Substantively, it suggests that for the base case of a UK respondent, increasing the inflation measure from one standard deviation below its mean to one standard deviation above while holding the other variables at their means, raises the probability of an "inflation" response by 12 percentage points. This estimate of a positive correlation between inflation performance and the INFLATION PRIORITY variable is replicated for Models 2 
through $5 .{ }^{28}$ The finding is consistent with both the inclusion of an inflation variable in the utility or loss functions in theoretical political economy models and with the large public opinion literature suggesting that the public dislikes inflation.

The estimated coefficient for Model 1 for the variable UNEMPLOYMENT is -0.059 with a standard error of 0.026 . As expected, unemployment is negatively correlated with the probability that a respondent places priority on inflation. The magnitude of this effect is comparable to that of inflation. Again for the base case UK respondent, increasing the unemployment variable from one standard deviation below its mean to one standard deviation above while holding the other variables constant at their means, lowers the probability of an "inflation" response by 12 percentage points. This estimate is also robust across Models 2 through 5 and consistent with previous theoretical and empirical research that specifies the macroeconomic preferences of the public. ${ }^{29}$

The more important results reported in Table 3 are the coefficients on the country indicator variables. Recall that the UK is the omitted country, so the coefficient estimates indicate whether, holding the other variables constant, inflation aversion among citizens is on average higher or lower than in the UK. The estimates range from -0.776 with a standard error of 0.170 for Sweden to 0.347 with a standard error 0.042 for Australia. This, of course, suggests that controlling for economic performance, Swedish citizens are significantly less inflation-averse than UK citizens, but that Australians are significantly more so. Specifically, at the same average level of economic performance, the average Swedish citizen is estimated to have an expected probability of placing priority on inflation of 0.23 , compared to 0.40 for the UK and 0.48 for Australia.

Note that only by controlling for economic context are comparisons of national differences in the INFLATION PRIORITY measure informative. The estimates allow a rough empirical test of whether it is reasonable to assume-as most political economy models do-that inflation aversion is constant across countries. Clearly, it is not, and the pattern of the estimates of country dummy variables is broadly consistent with many stylized descriptions of relative inflation aversion in the mass publics of advanced economies. For example, Italy and France seem, on average, to have lower inflation aversion compared to Germany and the United States. There are, of course, exceptions, and many more surveys over different points in the business cycle would be necessary to arrive at a reliable ordering. Nonetheless,

28. For Model 5, where control variables are included that measure the costs of inflation to national economic welfare, the estimate is, as expected, slightly smaller in magnitude with a relatively larger standard error ( $p$-value of 0.14$)$.

29. In alternative specifications, some combination of the unemployment rate, the natural rate of unemployment, and/or the difference between these was included in the model. The results from these analyses broadly confirmed the correlation between real economic performance and the macroeconomic priorities of citizens. These analyses did not allow for reliable inferences about whether citizens' macroeconomic priorities were consistent with a sophisticated natural rate model. See Sekhon 1999 for such an analysis. 
the results in Table 3 suggest that there is significant variation in national inflation aversion, controlling for economic context. Inflation aversion, controlling for economic context, is, in fact, what the parameters $a$ and $b$ in the Barro-Gordon loss function (and similar variations) refer to. Consequently, the cross-country variation documented in Table 3 suggests that exchange-rate and currency union political economy models which include multiple country loss functions should allow for variation in preferences (parameters $a$ and $b$ should be indexed by country) as well as variation in industrial structure and economic institutions. The penultimate section of the article offers a preliminary discussion of what some of the consequences of country differences in inflation aversion may be for standard political economy models.

The theoretical discussion has suggested that one possible explanation for crosscountry variation in inflation aversion is differences in the composition of individuals within a country. The coefficient estimates for Models 2, 3, and 4 reported in Table 4 suggest why this is a reasonable possibility. These specifications add individual-level regressors to determine if certain characteristics make individuals more or less inflation-averse. The results in Table 4 indicate that labor market status, income, gender, and political ideology are all correlated with individuals' macroeconomic priorities.

For Model 2, the coefficient estimate for the INCOME QUARTILE variable is 0.079 with a standard error of 0.016 , suggesting that higher-income individuals with fewer

TABLE 4. Determinants of inflation aversion: Models 2-4

\begin{tabular}{|c|c|c|c|c|c|c|c|c|c|}
\hline \multirow[b]{2}{*}{ Regressor } & \multicolumn{3}{|c|}{ Model 2} & \multicolumn{3}{|c|}{ Model 3} & \multicolumn{3}{|c|}{ Model 4} \\
\hline & Coefficient & S.E. & p-value & Coefficient & S.E. & p-value & Coefficient & S.E. & $p$-value \\
\hline INFLATION & 0.065 & 0.022 & 0.003 & 0.063 & 0.022 & 0.003 & 0.068 & 0.022 & 0.002 \\
\hline UNEMPLOYMENT & -0.060 & 0.027 & 0.024 & -0.062 & 0.028 & 0.029 & -0.062 & 0.026 & 0.017 \\
\hline INCOME QUARTILE & 0.079 & 0.016 & 0.000 & 0.071 & 0.016 & 0.000 & 0.052 & 0.016 & 0.001 \\
\hline UNEMPLOYED & -0.251 & 0.035 & 0.000 & -0.233 & 0.033 & 0.000 & -0.188 & 0.037 & 0.000 \\
\hline AGE & 0.004 & 0.002 & 0.011 & 0.003 & 0.002 & 0.060 & 0.002 & 0.002 & 0.147 \\
\hline GENDER & -0.237 & 0.030 & 0.000 & -0.238 & 0.029 & 0.000 & -0.242 & 0.027 & 0.000 \\
\hline EDUCATION YEARS & -0.001 & 0.008 & 0.902 & -0.001 & 0.007 & 0.862 & -0.007 & 0.007 & 0.345 \\
\hline POLITICAL IDEOLOGY & & & & 0.083 & 0.007 & 0.000 & & & \\
\hline PARTY & & & & & & & 0.307 & 0.023 & 0.000 \\
\hline $1980 \mathrm{~s}$ & 0.178 & 0.197 & 0.367 & 0.186 & 0.197 & 0.343 & 0.201 & 0.198 & 0.311 \\
\hline $1990 \mathrm{~s}$ & 0.390 & 0.174 & 0.025 & 0.404 & 0.175 & 0.021 & 0.428 & 0.175 & 0.014 \\
\hline Constant & -0.719 & 0.350 & 0.040 & -1.077 & 0.365 & 0.003 & -1.475 & 0.343 & 0.000 \\
\hline Country fixed effects & Yes & & & Yes & & & Yes & & \\
\hline Observations & 55,194 & & & 55,194 & & & 55,194 & & \\
\hline
\end{tabular}

Note: These results are multiple-imputation estimates of logit regression coefficients based on five imputed data sets. S.E. = standard error. The standard errors are country-clustered robust standard errors. The dependent variable is INFLATION PRIORITY. 
risks of actually experiencing unemployment are generally more inflation-averse. ${ }^{30}$ This result is not sensitive to changes in conditioning variables and holds across Models 2 through 5. The impact of unemployment risk is also evident in the estimated effect of being unemployed. For Model 2, the estimated coefficient for UNEMPLOYED is -0.251 with a standard error of 0.035 . This finding is also robust across different specifications. These results are consistent with the hypothesis that the distributive consequences of economic performance-specifically individual differences in labor market risks - affect macroeconomic priorities. The results for the demographic variables are also of interest. For Model 2, the estimated coefficient for the GENDER variable is -0.237 with a standard error of 0.030 . This indicates that women are, all else being equal, less likely to place priority on curbing inflation than men. While this result is open to interpretation, it may be a function of differences in labor market risks by sex not measured by the other variables in the model. The estimates for Model 2 also indicate that older respondents may be relatively more inflation-averse, but that there is no significant correlation between education and macroeconomic priorities. ${ }^{31}$ The positive effect for age is consistent with expectations if older individuals are more likely to own nominal assets and receive fixed nominal incomes. ${ }^{32}$

The final results reported in Table 4 that merit attention are the estimates for the impact of political identity on macroeconomic priorities. The estimates for both the POLITICAL IDEOLOGY and PARTY measures of political identity suggest that conservatism is positively correlated with greater inflation aversion: individuals who identify with political conservatism place greater emphasis on price stability. As pointed out in the theoretical discussion, this result is consistent with a central assumption in the theoretical and empirical literature on partisan and rational partisan business cycles.

Overall, the estimates in Table 4 make it clear that differences in individual characteristics, particularly those that indicate variation in exposure to the distributional consequences of economic performance, affect respondents' macroeconomic priorities. Whether these characteristics may account for some of the crosscountry variation in inflation aversion documented in Table 3 is ambiguous. For this to be the case, there would have to be sufficient differences across countries in the relevant characteristics.

One way to evaluate this possible explanation is to calculate, using the estimates from Model 2, the difference between the expected probability of observing

30. This result is, of course, also consistent with the related ideas that higher-income individuals are better able to insure themselves against the risks of unemployment or that high national unemployment levels may be associated with increasing income inequality.

31. Note that the estimate for AGE is attenuated in Models 3 and 4, which add measures of political ideology and partisanship. Because these variables may be, in part, consequences of the demographic variables, this attenuation does not support the inference that the AGE variable has no effect.

32. Recall that the data do not allow directly testing for the impact of ownership of nominal assets and liabilities on macroeconomic priorities. See Scheve 2003. 
an "inflation" response when a hypothetical respondent has values of the individuallevel variables equal to the sample averages and the expected probability when this respondent has values equal to a specific country's averages, holding economic context constant. Again focusing attention on Sweden, the UK, and Australia, this difference is calculated to be $0.000,0.002$, and -0.005 respectively. This pattern, which holds generally, indicates that while the individual-level variables certainly help to explain variation in macroeconomic priorities across individuals, there is simply not enough variation in these measures across countries to account for much of the cross-national variation in inflation aversion.

An alternative set of explanations for cross-country variation in macroeconomic priorities involve characteristics of the national economic and political environment that affect the actual costs of inflation and unemployment. One such factor reviewed in the theoretical discussion is the demand for government revenue. There are potential economic benefits to inflation given that existing tax structures are distortionary. How important a consideration this is in evaluating the relative costs of inflation and unemployment is likely to depend on the demand for government revenue. Table 5 reports estimates of the impact of the demand for government revenue-as measured by the variables GOVERNMENT SPENDING

TABLE 5. Determinants of inflation aversion: Model 5

\begin{tabular}{lrrr}
\hline & & Model 5 & \\
& & & \\
\cline { 2 - 4 } Regressor & Coefficient & S.E. & p-value \\
\hline & & & \\
INFLATION & & & \\
UNEMPLOYMENT & -0.046 & 0.031 & 0.139 \\
DEBT & 0.004 & 0.035 & 0.003 \\
GOVERNMENT SPENDING & -0.072 & 0.024 & 0.343 \\
TRADE OPENNESS & -0.018 & 0.008 & 0.003 \\
FINANCIAL EMPLOYMENT & 0.078 & 0.044 & 0.073 \\
INCOME QUARTILE & 0.075 & 0.016 & 0.000 \\
UNEMPLOYED & -0.273 & 0.035 & 0.000 \\
AGE & 0.004 & 0.002 & 0.014 \\
GENDER & -0.239 & 0.030 & 0.000 \\
EDUCATION YEARS & 0.003 & 0.007 & 0.648 \\
1980S & 0.338 & 0.187 & 0.070 \\
1990s & 0.241 & 0.162 & 0.137 \\
Constant & 2.599 & 1.470 & 0.077 \\
Country fixed effects & Yes & & \\
& & &
\end{tabular}

Observations

55,194

Note: These results are multiple-imputation estimates of logit regression coefficients based on five imputed data sets. S.E. = standard error. The standard errors are country-clustered robust standard errors. The dependent variable is INFLATION PRIORITY. 
and DEBT — on the public's macroeconomic priorities. The coefficient estimate for the GOVERNMENT SPENDING variable is -0.072 with a standard error of 0.024 , indicating a significant negative correlation with the inflation aversion measure. This result is consistent with the argument that in those countries with greater revenue requirements, inflation is less costly and individuals are less likely to place emphasis on price stability. The coefficient estimate for the DEBT variable that was also expected to measure the demand for government revenue, however, is not significantly different from $0 .{ }^{33}$

The Model 5 specification also includes a measure of trade openness. The expectation is that inflation is more costly in more open economies, and so individuals will weigh inflation more heavily. The results are not, however, consistent with this hypothesis. The estimated effect of increasing trade openness is negative and statistically significant. Further investigation of the correlation between trade openness and the INFLATION PRIORITY dependent variable suggests that this negative correlation may be sensitive to the choice of conditioning variables. Consequently, I simply interpret the estimate as disconfirming the hypothesis of a positive relationship.

The estimates in Table 5 for the FINANCIAL EMPLOYMENT measure suggest that a large national financial sector is associated with greater inflation aversion. The coefficient estimate is 0.078 with a standard error of 0.044 ( $p$-value of 0.073 ). The result provides an individual-level mechanism that reinforces Posen's argument that the financial sector, particularly firms in traditional commercial lending, has a strong preference for price stability. It appears that a large financial sector may affect average levels of inflation aversion, perhaps directly through individuals employed in the sector and/or indirectly through the sector's influence on the media.

Overall, these national-level factors affecting the relative welfare costs of inflation and unemployment do have a systematic impact on individuals' macroeconomic priorities. To evaluate whether these factors account for cross-country variation, it is again instructive to compare the expected probability of observing an "inflation" response when a hypothetical respondent has values of these nationallevel variables equal to the sample averages and the expected probability when this respondent has values equal to a specific country's averages, holding economic context and the individual-level measures constant. Again focusing attention on Sweden, the UK, and Australia, this difference is calculated to be 0.101 , 0.018 , and -0.296 respectively. This means that the expected probability of ob-

33. One reason that the debt result may be relatively small in magnitude is that the analysis cannot control for the nominal assets held by individuals. If high levels of national debt mean that citizens hold more nominal assets, then this would attenuate the expected negative effect based on the demand for revenue. The inflationary finance interpretation of the strong correlation between government spending and macroeconomic priorities is made cautiously. It is, of course, possible that individuals in some countries simply have a stronger taste for employment protection and thus prefer higher levels of government spending and are less inflation-averse. 
serving an inflation response is 10 percentage points higher for Sweden if one assumes values for DEBT, GOVERNMENT SPENDING, FINANCIAL EMPLOYMENT, and TRADE OPENNESS that are equal to the sample averages for these variables rather than the actual averages for Sweden. There is substantial cross-national variation in these variables, and they contribute significantly in helping to explain variation in macroeconomic priorities across countries.

Finally, some of the cross-country variation in inflation aversion may also be because of differences in historical macroeconomic performance. Although the arguments that "historical experience matters" are often contradictory, it does seem likely that national differences in public information sets, determined in part by historical economic performance, play a role in the formation of macroeconomic priorities. It may be possible in future research with more data to assess explicitly the extent to which differences in average inflation aversion across countries can be tied to historical experiences.

The general idea that public information sets account for some of the differences across countries and time not explained by other factors receives some modest support in the logit regression estimates. Each specification includes a dichotomous variable indicating whether the respondent was queried in the 1980s and a similar indicator for the 1990s. The results indicate that, controlling for other factors such as current economic performance, placing priority on price stability is more likely for a respondent queried in the 1980s and 1990s than the 1970s. ${ }^{34}$ It is entirely possible that these differences are because of macroeconomic experiences with high and volatile inflation in many of the countries in the sample during the 1970s and early 1980s. These historical experiences may inform current assessments of the costs of inflation and thus the public's macroeconomic priorities.

\section{Theoretical Implications}

\section{Policymaking and Economic Outcomes}

The first and most obvious implication of cross-country variation in inflation aversion is that optimal monetary policies and economic outcomes will vary across countries simply as a function of preferences. To discuss this implication as well as those for institutional choice and international monetary cooperation, it is instructive to specify a simple model of macroeconomic policymaking. ${ }^{35}$

34. For Models 1-4, the estimates are statistically significant at the .05 level for the 1990s but not the 1980s. For Model 5, the estimate is significant at the .10 level for the 1980s and is significant at the .15 level for the $1990 \mathrm{~s}$.

35. The model discussed below is a standard framework for analyses of the political economy of macroeconomic policymaking. See, for example, Drazen 2000. 
Assume that the economy is described by the following supply function:

$$
U_{t}=-\left(\pi_{t}-\pi_{t}^{e}\right)+\varepsilon_{t}
$$

where $U_{t}$ equals the unemployment rate relative to the natural rate of unemployment, assumed for convenience to be equal to 0 . The value of $U_{t}$ in a given period $t$ depends on the difference between the actual rate of inflation, $\pi_{t}$, and the expected rate, $\pi_{t}^{e}$, and on a stochastic unemployment shock, $\varepsilon_{t} . \varepsilon_{t}$ is independently and identically distributed with mean 0 and variance $\sigma^{2}$.

The policymaker is assumed to have a loss function in every period of the general form of equation (1) simplified slightly for discussion purposes. Let

$$
L_{t}=\frac{1}{2}\left(U_{t}-K\right)^{2}+\frac{\theta}{2}\left(\pi_{t}\right)^{2}
$$

where $\theta>0$ is the inflation aversion parameter indicating the policymaker's assessment of the relative costs of inflation and unemployment [equivalent to the ratio of $b$ over $a$ in equation (1)]; and $K$ is the socially optimal unemployment rate [equivalent to the product of $k$ and $U_{t}^{n}$ in equation (1)]. As do Barro and Gordon, I assume that the policymaker targets a level of unemployment less than the natural rate, because some distortion makes the natural rate higher than what the policymaker believes is socially optimal and therefore that $K$ is negative (recall that in this section the natural rate is normalized to 0 ). This wedge is, of course, what generates the time consistency problem in models of monetary policymaking.

To start, however, consider the hypothetical case in which the policymaker is able to commit ex ante to an optimal rule. The timing of policymaking is then that first the policymaker announces a rule. Then, expectations, $\pi_{t}^{e}$, are formed assuming the rule will be followed, and private agents commit to nominal contracts. Then an economic shock $\varepsilon_{t}$ is realized and observed by the policymaker, who then sets $\pi_{t}$ according to the rule.

The optimal policy is calculated by substituting equation (2) into equation (3) and minimizing the expected value at $t-1\left(E_{t-1} L_{t}\right)$ subject to rational expectations under the assumption that the rule will be followed $\left(\pi_{t}^{e}=E_{t-1} \pi_{t}\right)$. The optimal policy rule is

$$
\pi_{t}=\frac{\varepsilon_{t}}{1+\theta}
$$

Under this rule, the average inflation rate will be 0 and the average unemployment rate will be at the natural rate-normalized to 0 in this model. Policy, however, will achieve unemployment stabilization in that it will respond to shocks to unemployment brought on by technology, financial crises, and so on. Suppose it was possible to implement such a rule-then the empirical results of this article have 
important implications for optimal policymaking. ${ }^{36}$ The analysis in the previous section suggests that $\theta$, the inflation aversion parameter, should be indexed across countries, as some countries-for example, Germany and Australia-apparently have higher values for this parameter than others-for example, Sweden and Portugal. Consequently, the optimal policy response to economic shocks differs across countries. Simply that Swedish citizens care more about unemployment stabilization than Australian citizens implies that policymakers in Sweden will maximize welfare by responding more aggressively to a given economic shock than policymakers in Australia. This result may be of particular importance for developing countries that are not included in the empirical analysis. Assuming that the existence of country heterogeneity in inflation aversion generalizes to these countries, it is obviously poor advice for international organizations and policy experts to recommend uniform policy responses to similar economic events.

The assumption made in the foregoing analysis is that policymakers are able to commit to the optimal rule. It is well known that this rule is not time-consistent in that, if expectations were really formed based on the rule, policymakers would have an incentive to depart from it when they actually go to set policy (assuming $K<0$ and there actually is a wedge).

According to this view, the more reasonable set of assumptions for the timing of policymaking are that first, inflation expectations, $\pi_{t}^{e}$, are formed. Next, an economic shock $\varepsilon_{t}$ is realized and observed by the policymaker, and finally, the policymaker sets $\pi_{t}$.

To calculate the resulting policy under these assumptions, again substitute equation (2) into equation (3). Then minimize with respect to $\pi_{t}$ treating $\pi_{t}^{e}$ as given. Then assume rational expectations so that $\pi_{t}^{e}=E_{t-1} \pi_{t}$. This yields the equality $\pi_{t}^{e}=(-1 / \theta) K$. Substituting, the equilibrium inflation rate is equal to

$$
\pi_{t}=-\frac{1}{\theta} K+\frac{\varepsilon_{t}}{1+\theta}
$$

Under period-by-period policymaking, the average inflation rate is $(-1 / \theta) K$ and the average unemployment rate will be at the natural rate. Again, policy will achieve some degree of unemployment stabilization but no more so than under the optimal rule discussed above. Thus the inability to commit to the optimal rule decreases welfare, as inflation is higher with no compensating gains in unemployment performance. For this model, the most important implication of the article's empirical results is that variation in inflation aversion will have a systematic effect on observed inflation, because inflation aversion determines the degree of inflationary bias. Thus empirical studies attempting to explain variation in inflation performance need to somehow account for cross-national variation in inflation aver-

36. This is not just a theoretical possibility, as Blinder 1998 argues that central banks target the natural rate of unemployment $(K=0)$ and so the time consistency problem does not arise in practice. 
sion to avoid bias in their estimations. ${ }^{37}$ It is also worth pointing out that expressions for both inflation and output volatility in this model are a function of inflation aversion $\left\{\operatorname{Var}(\pi)=(1 /[1+\theta])^{2} \sigma^{2}, \operatorname{Var}(U)=(\theta /[1+\theta])^{2} \sigma^{2}\right\}$. Consequently, empirical analyses that attempt to explain the volatility of inflation and unemployment also need to account for cross-national variance in inflation aversion (note that even for the optimal rule case, the inflation aversion parameter matters for expectations about the volatility of inflation and unemployment).

To illustrate the plausibility of the claim that inflation aversion among mass publics may be a significant factor in explaining variation in economic outcomes, I conducted a simple analysis evaluating the relationship between country estimates of inflation aversion based on the survey analysis in the previous section and average inflation outcomes. Because all twenty countries included in the study have surveys in the 1990s and because this decade makes up about 75 percent of the total individual observations in the data set, I focus the analysis of average inflation outcomes on the period 1990 to $1997 .{ }^{38}$ The variable ESTIMATED INFLATION AVERSION employs the parameter estimates from Model 1 reported in Table 3, and is equal to the predicted probability that a respondent from a particular country in the 1990 decade gives the "inflation" response assuming that the economic context (INFLATION and UNEMPLOYMENT) is equal to the average for the entire sample. In the analysis above, I have claimed that responses to the survey question, controlling for economic context, measure inflation aversion. Thus the predicted probability described above is a country-level measure of inflation aversion (alternatively the estimated coefficients on the country dummy variables for Model 1 could be used and all results reported here are the same employing this measure). The variable AVERAGE LOGGED INFLATION is equal to the average of the natural $\log$ of the change in the consumer price index for the years 1990 to 1997.

Figure 1 plots the variables AVERAGE LOGGED INFLATION and ESTIMATED INFLATION AVERSION and draws the relevant regression line. The graph reveals a negative correlation indicating that those countries with greater inflation aversion experienced lower average inflation outcomes. Table 6 reports the estimates for two ordinary least squares regressions of AVERAGE LOGGED INFLATION on ESTIMATED INFLATION AVERSiON. The results for Model 6 indicate that the observed negative correlation in Figure 1 is statistically significant, while the estimates for Model 7 suggest that the partial correlation is robust to including a measure of central bank independence. ${ }^{39}$ There are a number of obvious limitations to this

37. This point assumes, consistent with the model, that the public's welfare informs the policymaker's welfare. In frameworks for which this is not the case, as in a strong partisan account, the insight is not as telling (assuming a valid measure of the inflation aversion of the partisan group in power is employed).

38. If instead average inflation outcomes for the entire period of the survey data are analyzed (197697), the results are qualitatively the same.

39. The measure of central bank independence is the index developed by Cukierman, Webb, and Neyapti 1992. I use Keefer and Stasavage's 2002 update of this index for the 1990s-specifically I use 


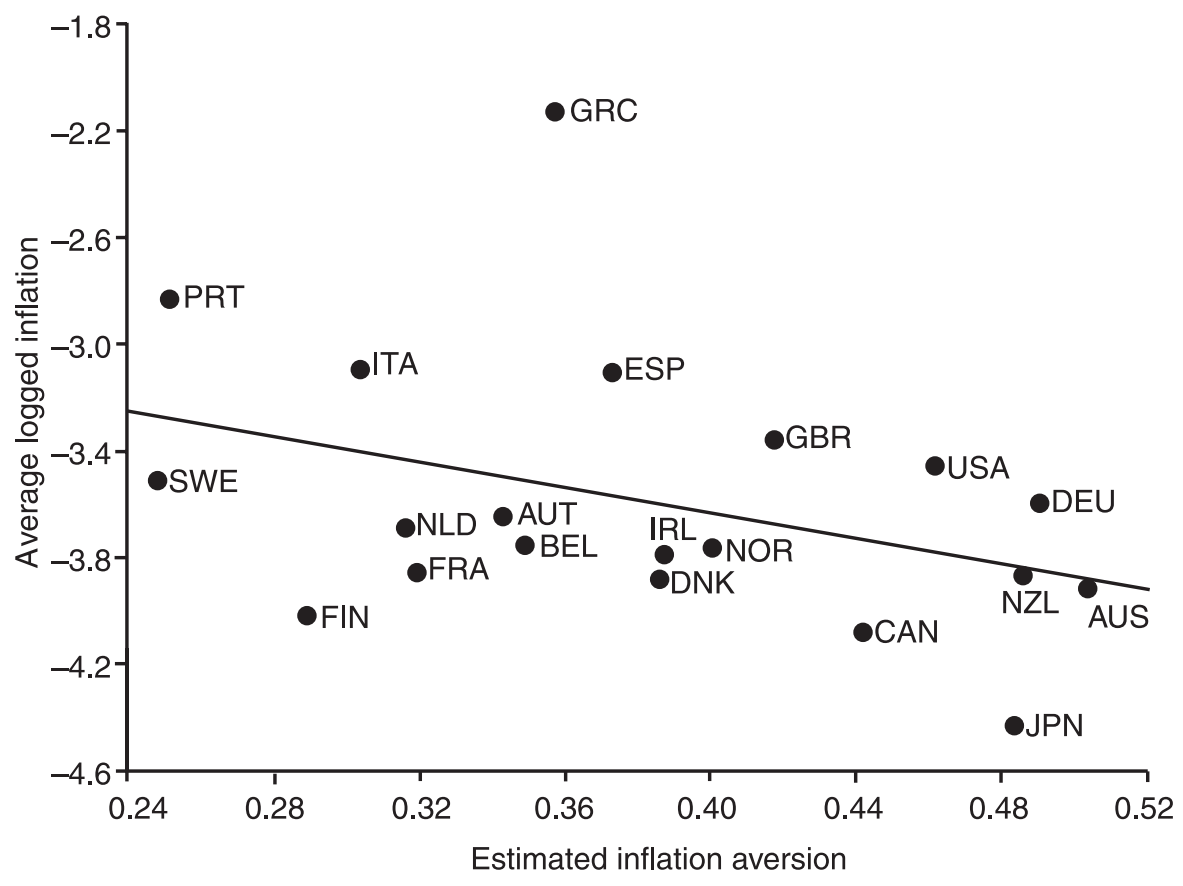

FIGURE 1. Average logged inflation by estimated inflation aversion

TABLE 6. Determinants of average logged inflation 1990-1997: Models 6-7.

\begin{tabular}{|c|c|c|c|c|c|c|}
\hline \multirow[b]{2}{*}{ Regressor } & \multicolumn{3}{|c|}{ Model 6} & \multicolumn{3}{|c|}{ Model 7} \\
\hline & Coefficient & S.E. & p-value & Coefficient & S.E. & $p$-value \\
\hline ESTIMATED INFLATION AVERSION & -2.377 & 1.118 & 0.048 & -1.985 & 0.928 & 0.047 \\
\hline CENTRAL BANK INDEPENDENCE & & & & 1.045 & 0.702 & 0.155 \\
\hline CONSTANT & -2.686 & 0.469 & 0.000 & -3.304 & 0.438 & 0.000 \\
\hline S.E.R. & 0.481 & & & 0.453 & & \\
\hline Observations & 20 & & & 20 & & \\
\hline
\end{tabular}

Note: These results are ordinary least squares regression coefficients. S.E. = standard error. The standard errors are heteroskedastic-consistent standard errors. The dependent variable is AVERAGE LOGGED INFLATION.

the measure for 1994 that is approximately the midpoint of the years in my analysis (their data does not allow for a calculation of the full 1990-97 average). I employ mean imputation for Portugal for which the central bank independence measure is missing. 
analysis. First, because the survey data are limited to twenty countries and there is insufficient data to develop time varying measures for each country, the analysis is based on a very small number of cross-sectional observations. Second, and related, the literature - employing larger data sets-has suggested a number of other regressors besides central bank independence that should be included in a more complete analysis. This point is perhaps not as telling as it may seem, as many institutional variables may be a consequence of inflation aversion and thus inappropriate control variables for an analysis seeking to estimate the effect of inflation aversion in the mass public on economic outcomes. Third, inflation aversion may be in part a consequence of economic outcomes. This is certainly possible, but if the idea is that experience with inflation makes citizens more concerned about its costs, then the bias from endogeneity results in a conservative estimate of the effect of inflation aversion on average inflation in this analysis.

Of course, many other objections common to small $N$ cross-sectional analyses could be raised. The point, however, is that common models of macroeconomic policymaking suggest that variation in inflation aversion may result in variation in economic outcomes. The survey analysis in this study demonstrates strong evidence of cross-national variation in inflation aversion. Thus inflation aversion in mass publics may be an important factor in explaining economic outcomes, and there is some evidence in Figure 1 and Table 6 that this is the case.

\section{Institutional Choice}

The second straightforward implication of cross-country variation in inflation aversion is that even countries that face similar objective economic environments may choose different macroeconomic policymaking institutions. The classic comparison to illustrate this point is the choice between policymaking under the discretionary, period-by-period regime described above and policymaking following a simple, credible, and easily monitored zero-inflation rule. The trade-off between these policymaking institutions is, of course, that the former generates inflation bias but some degree of stabilization, while the latter avoids bias but fails to respond to economic shocks. By comparing expected utility as defined in equation (3) under each institution given its equilibrium inflation and unemployment rates, it can be shown that the period-by-period regime is preferred if

$$
\sigma^{2}>\frac{(1+\theta)}{\theta} K^{2}
$$

Because $\sigma^{2}$ is the variance of $\varepsilon_{t}$, this result simply means that if unemployment shocks are large enough relative to the parameters $\theta$ and $K$ that determine the extent of inflation bias, the benefits of stabilization under the period-by-period regime outweigh the costs of greater inflation. Previous discussions of discretion versus simple rules have focused on how cross-country variations in economic 
structure that affect exposure to economic shocks are likely to influence this institutional choice. The empirical results establishing cross-country variation in inflation aversion suggest an additional consideration. The condition in equation (6) is easier to satisfy as inflation aversion $(\theta)$ increases, because this increase decreases the extent of inflation bias in the period-by-period policymaking regime. So somewhat counterintuitively, it is, all else being equal, less likely to be optimal for countries with higher inflation aversion to adopt the simple zero-inflation rule than for countries with lower levels of inflation aversion. It is beyond the scope of this discussion to evaluate this prediction systematically, and it is important to recognize that there are other institutional alternatives to discretion and simple rules. Nonetheless, it is interesting to note that the European Central Bank (ECB) has an explicit mandate for price stability (essentially a zero-inflation rule), while the U.S. Federal Reserve does not. The data presented in Figure 1 indicate that ten of the eleven countries for which the ECB controls policy have substantially lower levels of inflation aversion than the United States.

Although a wide variety of analyses of the choice of monetary institutions can similarly be informed by the consideration of cross-national variation in inflation aversion, ${ }^{40}$ the final example sketched here is the case of a country joining a monetary union. The dominant framework for examining this problem is the theory of optimal currency areas (OCA). This literature focuses primarily on identifying benefits to a country from joining a union such as reduced exchange-rate risks and transaction costs for international businesses, and on identifying costs such as foregoing the ability to use monetary policy to respond to country-specific macroeconomic shocks. The empirical results in this article demonstrating evidence of cross-country variation in inflation aversion suggest that the implications of country differences in preferences/objective functions should also be considered central to analyses of a country's decision to join a monetary union and to evaluations of alternative policymaking frameworks for such unions.

Analogous to the evaluation above of expected utility under the period-byperiod regime and the simple zero-inflation rule, one can compare a country's expected utility in and out of a monetary union assuming that the union and country face the same policy problem but have different preferences/objective functions [values of the parameters $K$ and $\theta$ in equation (3)] and respond to different economic outcomes (inflation, unemployment, and unemployment shocks for the entire currency area versus values for a single country). Although a full analysis of the consequences of variation in objective functions for a country's decision to join a monetary union is beyond the scope of this article, ${ }^{41}$ a few key observations are instructive. First, it can be shown that joining a monetary union can be equivalent to the appointment of an independent conservative central banker for those

40. Candidates include the family of "second-generation" models of monetary institutions that consider decisions about CBI and exchange-rate pegs simultaneously. See Bernhard, Broz, and Clark 2002.

41. See Alesina and Grilli 1992 and 1993; and Garrett 1993. 
countries with relatively low levels of inflation aversion. This effect, of course, has the same benefits (lower inflation and inflation volatility) and costs (higher output volatility) as the appointment of a conservative central banker. Second, if countries are assumed to choose the inflation aversion of the currency union's policymaking body, their preferences regarding this characteristic of the policymaker will depend on interactions between their levels of inflation aversion, the relative variance of country-specific and currency area-wide unemployment shocks, and the covariance between these shocks. For example, all else being equal, the less positively correlated shocks are in the union, the more conservative is the preferred currency union policymaker. Third, if the choice of the inflation aversion of the currency union policymaker is made at the same time as the decision to join the union, then even under the most optimistic assumptions about the relative variance and correlation of economic shocks, cross-national variation in inflation aversion can make it such that there may be no level of inflation aversion for the currency union policymaker that leaves all potential entrants better off for having joined the union.

\section{Conclusion}

This article provides new evidence on the determinants of individual macroeconomic priorities based on survey data in twenty advanced economies. There are three main empirical results. First, the results suggest that economic context has a substantial impact on the public's economic objectives in a way broadly consistent with the specification of utility/loss functions in the theoretical political economy literature. Second, the results suggest that there is significant cross-country variation in inflation aversion, controlling for economic context. Third, some of this variation is accounted for by national-level factors affecting the aggregate costs of inflation and unemployment. The empirical estimates in this article suggest that the demand for government revenue and the size and structure of the financial sector partially explain cross-country variation in inflation aversion, controlling for economic context and the individual characteristics of survey respondents.

Overall, the findings in this article suggest a number of questions for future research. As discussed in the previous section, the existence of cross-country variation in inflation aversion, controlling for economic context, has significant implications for optimal monetary policymaking, for explanations of variation in economic outcomes, and for models of alternative institutional frameworks for policymaking. The foregoing discussion only sketched some of the most obvious consequences, and further theoretical work could productively incorporate the existence of country differences in macroeconomic priorities into explanations of institutional choice, international policy coordination, policy choice, outcomes, or the associated political conflict over these decisions. The results in this article on the role of individual characteristics in determining individual macroeconomic priorities may also be useful for this literature, particularly studies of why countries 
adopt the monetary institutions that they do. The role of distributive conflict among groups in society is central to debate about this question. ${ }^{42}$ The findings of this article suggest that those distributive conflicts are evident in the electorate as well as among firms in various sectors of the economy. The results in the article may also be useful in future empirical studies explaining variation in economic outcomes, particularly investigations of the effect of monetary institutions. As various scholars have made clear, evaluating the effect of these institutions depends on first specifying preferences. ${ }^{43}$ This article provides substantial evidence that there is sufficient variation in public macroeconomic priorities across countries for the specification of preferences to be significantly improved by accounting for the relative inflation aversion of citizens.

\section{Appendix}

\section{Data Description}

The surveys used in the analysis are Eurobarometers (EB) 5.0 (1976) and 48.0 (1997) and the 1985, 1990, and 1996 waves of the International Social Survey Program (ISSP). The EB and ISSP are cross-country surveys that collect information on the current economic and political opinions of representative samples of individuals in each country. The sources for each country year used to construct the dependent variable, INFLATION PRIORITY, are reported in Table 7. For the EB 5.0 data, the English version of the question is: "What do you think the national government should give greater priority to, curbing inflation or reducing unemployment?" Individuals were coded 1 if they gave the "inflation" response and 0 if they gave the "unemployment" response. Missing data was imputed using the procedures described in the next section of the Appendix. The question for the EB 48.0 data differed in the responses coded. The English version of the question is: "Do you think the national government should give higher priority to reducing inflation or higher priority to reducing unemployment?". Answers were coded on a 5-point scale ranging from "a lot higher priority on reducing unemployment" to "a lot higher priority on reducing inflation." This scale was collapsed to a dichotomy with "inflation" answers coded a 1 and "unemployment" answers coded a 0. The dependent variable, INFLATION PRIORITY, was coded using the same imputation and coding rules described above. Finally, data from all three International Social Survey Program (ISSP) studies are based on responses to the question: "If the government had to choose between keeping down inflation or keeping down unemployment, to which do you think it should give highest priority?" Again, responses indicating "inflation" were coded 1 , and those indicating "unemployment" were coded 0 . The same procedures described above were used to construct the dependent variable INFLATION PRIORITY.

42. See Frieden 1991; and Bearce 2003.

43. See Garrett 1993; Posen 1995; and Franzese 1999 and 2002. 
TABLE 7. Data description

\begin{tabular}{|c|c|c|c|c|c|}
\hline Country & Year & Source & Country & Year & Source \\
\hline Australia & 1986 & ISSP 1985 & Ireland & 1996 & ISSP 1996 \\
\hline Australia & 1990 & ISSP 1990 & Ireland & 1997 & Eurobarometer 48.0 \\
\hline Australia & 1996 & ISSP 1996 & Italy & 1985 & ISSP 1985 \\
\hline Austria & 1986 & ISSP 1985 & Italy & 1990 & ISSP 1990 \\
\hline Austria & 1997 & Eurobarometer 48.0 & Italy & 1996 & ISSP 1996 \\
\hline Belgium & 1976 & Eurobarometer 5.0 & Italy & 1997 & Eurobarometer 48.0 \\
\hline Belgium & 1997 & Eurobarometer 48.0 & Japan & 1996 & ISSP 1996 \\
\hline Canada & 1996 & ISSP 1996 & Netherlands & 1976 & Eurobarometer 5.0 \\
\hline Denmark & 1976 & Eurobarometer 5.0 & Netherlands & 1997 & Eurobarometer 48.0 \\
\hline Denmark & 1997 & Eurobarometer 48.0 & New Zealand & 1997 & ISSP 1996 \\
\hline Finland & 1997 & Eurobarometer 48.0 & Norway & 1990 & ISSP 1990 \\
\hline France & 1976 & Eurobarometer 5.0 & Portugal & 1997 & Eurobarometer 48.0 \\
\hline France & 1997 & Eurobarometer 48.0 & Spain & 1996 & ISSP 1996 \\
\hline France & 1997 & ISSP 1996 & Spain & 1997 & Eurobarometer 48.0 \\
\hline Germany & 1976 & Eurobarometer 5.0 & Sweden & 1997 & Eurobarometer 48.0 \\
\hline Germany & 1985 & ISSP 1985 & UK & 1976 & Eurobarometer 5.0 \\
\hline Germany & 1990 & ISSP 1990 & UK & 1985 & ISSP 1985 \\
\hline Germany & 1996 & ISSP 1996 & UK & 1990 & ISSP 1990 \\
\hline Germany & 1997 & Eurobarometer 48.0 & UK & 1997 & Eurobarometer 48.0 \\
\hline Greece & 1997 & Eurobarometer 48.0 & US & 1985 & ISSP 1985 \\
\hline Ireland & 1976 & Eurobarometer 5.0 & US & 1990 & ISSP 1990 \\
\hline Ireland & 1991 & ISSP 1990 & US & 1996 & ISSP 1996 \\
\hline
\end{tabular}

\section{Methodology for Missing Data}

The data constructed for this article are not fully observed. The sources of the missing data range from the refusal of survey respondents to answer particular items in some surveys to some questions not being asked at all in certain surveys. Incomplete data, whatever the source, can create a number of serious problems for making valid statistical inferences. The most general and extensively researched approach for dealing with missing data problems is "multiple imputation." King, Honaker, Joseph, and Scheve; Schafer; and Rubin describe the advantages of multiple imputation over alternative strategies for addressing missing data problems for survey analyses like those presented in this article. ${ }^{44}$

The approach has several variations but always involves three main steps. First, some algorithm is used to impute values for the missing data. In this step, $m(m>1)$ "complete" data sets are created consisting of all the observed data and imputations for the missing values. The second step simply involves analyzing each of the $m$ data sets using standard complete-data statistical methods. The final step combines the parameter estimates and variances from the $m$ complete-data analyses to form a single set of parameter estimates and variances. Importantly, this step systematically accounts for variation across the $m$ analyses due to missing data in addition to ordinary sample variation. 
The first step in the multiple-imputation procedures was to create imputations in the missing data cells for all the variables used in the analysis. The variables in the imputation model included all those used in the analyses reported above as well as additional information from the surveys determined to be helpful in predicting the missing data. The imputation model included two similar measures of inflation aversion. In addition to INFLATION PRIORITY, a three-category ordinal variable was included that accounted for the fact that the question wording in one of the five surveys discussed in the previous section allowed for a neutral response. In constructing INFLATION PRIORITY, these neutral responses were coded missing but then imputed in the imputation stage of the analysis. ${ }^{45}$ All the results reported in the text are robust to using either the INFLATION PRIORITY variable or the three-category ordinal variable to measure inflation aversion. Altogether I imputed five complete individuallevel data sets for the pooled survey data. The exact imputation algorithm used is known by the acronym "EMis" because to generate imputations it combines a well-known Expectation Maximization missing data algorithm with a round of importance sampling. King et al. provide a complete explanation of the use of this algorithm for missing data problems. ${ }^{46}$ The imputation model was multivariate normal with a slight ridge prior. ${ }^{47}$ The final data sets contain completed observations equal to the actual number of individuals in the survey. Also, all data sets contain the same nonimputed information; they differ only in the imputations for missing data.

The second step in the multiple-imputation analysis was to run the various logit models separately on each of the five final data sets. The last multiple-imputation step was to combine the five sets of estimation results for each specification to obtain a single set of estimated parameter means and variances. The single set of estimated means is simply the arithmetic average of the five different estimation results. The single set of estimated variances is more complicated than a simple average because, as mentioned above, these variances account for both the ordinary within-sample variation and the between-sample variation due to missing data. See King et al. and Schafer for a complete description of these variances. $^{48}$

\section{References}

Alesina, Alberto. 1987. Macroeconomic Policy in a Two-Party System as a Repeated Game. Quarterly Journal of Economics 102 (3):651-78.

Alesina, Alberto, and Vittorio Grilli. 1992. The European Central Bank: Reshaping Monetary Politics in Europe. In Establishing a Central Bank, Issues in Europe and Lessons from the U.S., edited by Matthew B. Canzoneri, Vittorio Grilli, and Paul Masson, 49-77. Cambridge: Cambridge University Press.

45. See King, Honaker, Joseph, and Scheve 2001; and Schafer 1997 for discussion of why it is optimal to impute the dependent variable as well as the independent variables. The key intuition is that the goal of the imputation is to preserve the observed distribution of the data. The imputations do this in a way that allows all of the existing information in the observed data set to be included in standard statistical analyses. The imputations themselves add no new information.

46. King, Honaker, Joseph, and Scheve 2001.

47. The imputation procedures were implemented using Amelia: A Program for Missing Data, Honaker et al., 2000.

48. See King, Honaker, Joseph, and Scheve 2001; and Schafer 1997. 
1993. On the Feasibility of a One-Speed or Multi-Speed European Monetary Union. Economics and Politics 5 (2):145-65.

Alesina, Alberto, Nouriel Roubini, and Gerald D. Cohen. 1997. Political Cycles and the Macroeconomy. Cambridge, Mass.: MIT Press.

Alt, James E. 1979. The Politics of Economic Decline: Economic Management and Political Behavior in Britain Since 1964. Cambridge: Cambridge University Press.

Anderson, Christopher. 1995. Blaming the Government: Citizens and the Economy in Five European Democracies. London: M.E. Sharpe.

Bakhshi, Hasan, Andrew G. Haldane, and Neal Hatch. 1997. Quantifying Some Benefits of Price Stability. Bank of England Quarterly Bulletin 37 (August):274-84.

Barro, Robert, and David Gordon. 1983a. Rules, Discretion, and Reputation in a Model of Monetary Policy. Journal of Monetary Economics 12 (1):101-21.

- 1983b. A Positive Theory of Monetary Policy in a Natural Rate Model. Journal of Political Economy 91 (4):589-610.

Bearce, David H. 2003. Societal Preferences, Partisan Agents, and Monetary Policy Outcomes. International Organization 57 (2):373-410.

Bernhard, William, J. Lawrence Broz, and William Roberts Clark. 2002. The Political Economy of Monetary Institutions. International Organization 56 (4):693-723.

Blinder, Alan S. 1998. Central Banking in Theory and Practice. Cambridge, Mass.: MIT Press.

Blinder, Alan S., and Howard Y. Esaki. 1978. Macroeconomic Activity and Income Distribution in the Postwar United States. The Review of Economics and Statistics 60 (4):604-9.

Cukierman, Alex, Steven B. Webb, and Bilin Neyapti. 1992. Measuring the Independence of Central Banks and Its Effect on Policy Outcomes. World Bank Economic Review 6 (3):353-98.

Di Tella, Rafael, Robert MacCulloch, and Andrew Oswald. 2001. Preferences over Inflation and Unemployment: Evidence from Surveys of Happiness. American Economic Review 91 (1):335-41.

Drazen, Allan. 2000. Political Economy in Macroeconomics. Princeton, N.J.: Princeton University Press.

Feldstein, Martin S. 1997. The Costs and Benefits of Going from Low Inflation to Price Stability. In Reducing Inflation: Motivation and Strategy, edited by Christina D. Romer and David H. Romer, 123-56. Chicago: University of Chicago Press.

Franzese, Robert J. 1999. Partially Independent Central Banks, Politically Responsive Governments, and Inflation. American Journal of Political Science 43 (3):681-706.

- 2002. Macroeconomic Policies of Developed Democracies. Cambridge: Cambridge University Press.

Frieden, Jeffry A. 1991. Invested Interests: The Politics of National Economic Policies in a World of Global Finance. International Organization 45 (4):425-51.

- 2002. Real Sources of European Currency Policy: Sectoral Interests and European Monetary Integration. International Organization 56 (4):831-60.

Garrett, Geoffrey. 1993. The Politics of Maastricht. Economics and Politics 5 (2):105-23.

Garrett, Geoffrey, and Christopher Way. 1999. Public Sector Unions, Corporatism, and Macroeconomic Performance. Comparative Political Studies 32 (4):411-34.

Hall, Peter A. 1993. Policy Paradigms, Social Learning, and the State: The Case of Economic Policymaking in Britain. Comparative Politics 25 (3):275-96.

Hayo, Bernd. 1998. Inflation Culture, Central Bank Independence and Price Stability. European Journal of Political Economy 14 (2):241-63.

Hibbs, Douglas A. 1979. The Mass Public and Macroeconomic Performance: The Dynamics of Public Opinion Toward Unemployment and Inflation. American Journal of Political Science 23 (4):705-31.

—. 1987a. The Political Economy of Industrial Democracies. Cambridge, Mass.: Harvard University Press.

- 1987b. The American Political Economy: Macroeconomics and Electoral Politics. Cambridge, Mass.: Harvard University Press.

Hibbs, Douglas A., and Christopher Dennis. 1988. Income Distribution in the United States. The American Political Science Review 82 (2):467-90. 
Hibbs, Douglas A., R. Douglas Rivers, and Nicolas Vasilatos. 1982. On the Demand for Economic Outcomes: Macroeconomic Performance and Mass Political Support in the United States, Great Britain, and Germany. Journal of Politics 44 (2):426-62.

Honaker, James, Anne Joseph, Gary King, and Kenneth Scheve. 2000. Amelia: A Program for Missing Data, Gauss version 2.0. Cambridge, Mass.: Harvard University.

International Social Survey Program (ISSP). 1985. Role of Government I. Cologne, Germany: Zentralarchiv für Empirische Sozialforschung.

1990. Role of Government II. Cologne, Germany: Zentralarchiv für Empirische Sozialforschung.

1996. Role of Government III. Cologne, Germany: Zentralarchiv für Empirische Sozialforschung.

Iversen, Torben. 1999. Contested Economic Institutions: The Politics of Macroeconomics and Wage Bargaining in Advanced Democracies. New York: Cambridge University Press.

Keefer, Philip, and David Stasavage. 2002. Checks and Balances, Private Information, and the Credibility of Monetary Commitments. International Organization 56 (4):751-74.

King, Gary, James Honaker, Anne Joseph, and Kenneth Scheve. 2001. Analyzing Incomplete Political Science Data: An Alternative Algorithm for Multiple Imputation. American Political Science Review 95 (1):49-69.

King, Gary, Christopher J. L. Murray, Joshua A. Salomon, and Ajay Tandon. Forthcoming. Enhancing the Validity and Cross-Cultural Comparability of Survey Research. American Political Science Review 97 (4).

Kramer, Gerald. 1971. Short-Term Fluctuations in U.S. Voting Behavior: 1896-1964. American Political Science Review 65 (1):131-43.

Kydland, Finn E., and Edward C. Prescott. 1977. Rules Rather Than Discretion: The Inconsistency of Optimal Plans. Journal of Political Economy 85 (3):473-92.

Lane, Philip. 1997. Inflation in Open Economies. Journal of International Economics 42 (3-4):327-47.

Lewis-Beck, Michael S. 1988. Economics and Elections: The Major Western Democracies. Ann Arbor: University of Michigan Press.

Lohmann, Susanne. 1992. Optimal Commitment in Monetary Policy: Credibility Versus Flexibility. American Economic Review 82 (1):273-86.

McNamara, Kathleen. 1999. Consensus and Constraint: Ideas and Capital Mobility in European Monetary Integration. Journal of Common Market Studies 37 (3):455-76.

Melich, Anna. 1997. Eurobarometer 48.0 [computer file]. INRA (Europe), Brussels [producer], 1998. Ann Arbor, Mich.: Inter-University Consortium for Political and Social Research/ Cologne, Germany: Zentralarchiv fuer Empirische Sozialforschung [distributors], 1999.

Moulton, Brent R. 1990. An Illustration of a Pitfall in Estimating the Effects of Aggregate Variables on Micro Units. The Review of Economics and Statistics 72 (2):334-38.

Organization for Economic Cooperation and Development (OECD). 2001. OECD Statistical Compendium. Paris: OECD.

Posen, Adam. 1995. Declarations Are Not Enough: Financial Sector Sources of Central Bank Independence. NBER Macroeconomics Annual 10:253-74.

Powell, G. Bingham, and Guy D. Whitten. 1993. A Cross-National Analysis of Economic Voting: Taking Account of Political Context. American Journal of Political Science 37 (2):391-414.

Rabier, Jacques-Rene, and Ronald Inglehart. 1976. Eurobarometer 5.0 [computer file]. INRA (Europe), Brussels [producer], 1978. Ann Arbor, Mich.: Inter-University Consortium for Political and Social Research/Cologne, Germany: Zentralarchiv für Empirische Sozialforschung [distributors], 1978.

Rogoff, Kenneth. 1985. The Optimal Degree of Commitment to an Intermediate Monetary Target. Quarterly Journal of Economics 100 (4):1169-89.

Romer, David. 1993. Openness and Inflation: Theory and Evidence. Quarterly Journal of Economics 108 (4):869-903.

Rubin, Donald B. 1987. Multiple Imputation for Nonresponse in Surveys. New York: Wiley.

Schafer, Joseph L. 1997. Analysis of Incomplete Multivariate Data. London: Chapman \& Hall. 
Scheve, Kenneth. 2003. Public Demand for Low Inflation. Bank of England Working Paper No. 172. London: Bank of England.

Sekhon, Jasjeet. 1999. The Economic Sophistication of American Politics: American Public Opinion and Monetary Policy, 1973-1993. Unpublished manuscript, Cornell University, Ithaca, N.Y.

Shiller, Robert J. 1997. Why Do People Dislike Inflation? In Reducing Inflation: Motivation and Strategy, edited by Christina D. Romer and David H. Romer, 13-65. Chicago: University of Chicago Press.

van Lelyveld, Iman. 1999. Inflation and Unemployment? Who Cares? European Journal of Political Economy 15 (3):463-84.

Walsh, Carl E. 1995. Optimal Contracts for Central Bankers. American Economic Review 85 (1):150-67.

World Bank. 2001. World Development Indicators. Washington D.C.: International Bank for Reconstruction and Development, World Bank. 